\title{
Castleman disease: an uncommon diagnosis in pediatrics
}

\author{
Paula Martinez Vianna ${ }^{a}$, Paulo Galluzzi Pastore ${ }^{a}$, Lilian Cristofani ${ }^{b}$, \\ Sheila Aparecida Coelho Siqueira ${ }^{a}$, Vera Aldreda, \\ Fernando Peixoto Ferraz de Campos $^{c}$, Maria Claudia Nogueira Zerbini ${ }^{\mathrm{a}, \mathrm{d}}$
}

Vianna PM, Pastore PG, Cristofani L, et al. Castleman disease: an uncommon diagnosis in pediatrics. Autopsy Case Rep [Internet]. 2012; 2(3):39-44. http://dx.doi.org/10.4322/acr.2012.024

\section{ABSTRACT}

First described by Dr. Benjamin Castleman in 1956, Castleman disease is an uncommon disease of an etiology that is not yet thoroughly known. Three distinct histological subtypes have already been described: hyaline-vascular-, plasma cell-, and human herpes virus 8-associated variant, clinically distinguished in multi or unicentric types. Castleman disease is occasionally diagnosed in children, but more often in young adults, with no gender predominance. The symptoms are rather heterogeneous, varying from an asymptomatic mass in the unicentric Castleman disease type, to life-threatening systemic inflammatory state with systemic symptoms in the multicentric Castleman disease type. The authors report a case of a 15-year-old boy who sought medical attention due to a cervical tumor mass, without systemic symptoms. Pathology exam of the excised mass diagnosed a very typical example of the hyaline-vascular unicentric type of Castleman disease.

Keywords: Lymphoproliferative disorders; Giant lymph node hyperplasia; Biopsy; Lymph node excision.

\section{CASE REPORT}

A 15-year-old male patient sought medical attention complaining of a one-week history of pain on the right side of the neck and sore throat. The patient denied fever and other symptoms. Antibiotic and analgesic were prescribed. Thereafter the patient referred the appearance of painless tumor mass on the right side of the neck.

On physical static examination, a $4.5 \mathrm{~cm}$ nodule was evident on the right side of the neck. On palpation the tumor was painless, hard, not fixed to the surrounding tissues, and showed well-defined limits. The rest of the physical examination was unremarkable.

Ultrasonography revealed two enlarged right cervical lymph nodes measuring up to $3.0 \mathrm{~cm}$ and one increased lymph node on the left cervical chain measuring $1.0 \mathrm{~cm}$. General laboratory workup was normal and serology for toxoplasmosis,

\footnotetext{
a Department of Pathology - Faculdade de Medicina - Universidade de São Paulo, São Paulo/SP - Brazil.

${ }^{\text {b }}$ Department of Pediatrics - Faculdade de Medicina - Universidade de São Paulo, São Paulo/SP - Brazil.

c Department of Internal Medicine - Hospital Universitário - Universidade de São Paulo, São Paulo/SP - Brazil.

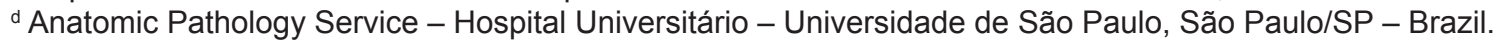


cytomegalovirus, hepatitis B virus, hepatitis $C$ virus, hepatitis $A$ virus, human immunodeficiency virus (HIV), and syphilis were all negative.

An excisional biopsy was performed and five irregular fragments consisting of lymphoid tissue were removed. The largest lymph node fragment measured $4.5 \times 3.2 \times 1.9 \mathrm{~cm}$ and was characterized by a brownish color at the cut surface and by a fibroelastic consistency.

Samples of excised tissues were incubated in a specific mycobacterial culture medium, which failed to show bacterial growth. The histopathological evaluation revealed lymphoid hyperplasia with an increased number of germinal centers and distinctive follicles with expanded mantle zones forming concentric rings surrounding one or more atrophic germinal centers. The germinal centers showed marked vascular proliferation, often with a single prominent penetrating hyalinised vessel. The interfollicular area also revealed marked vascular proliferation with hyaline change. These findings were consistent with the hyaline vascular type of Castleman disease (Figure 1).

An immunohistochemical study characterized better the diagnosis of Castleman disease and excluded lymphoma. The markers were: CD20 (B lymphocytes), CD3 (T lymphocytes), CD138 (plasma cells), CD21 (follicular dendritic cells), CD34 (vessels), HHV-8 (human herpes virus 8), KI67 (proliferative index, germinative centers), CD23 (follicular dendritic cells), and IgD (mantle cells) (Figure 2).

\section{DISCUSSION}

Castleman disease, also called angiofollicular lymphoid hyperplasia or giant lymph node hyperplasia, ${ }^{1}$ was first described in 1956 by Dr. Benjamin Castleman, when he published a series of 13 cases collected from the Massachusetts General Hospital, the Armed Forces Institute of Pathology, and the University of Havana. He defined it as a
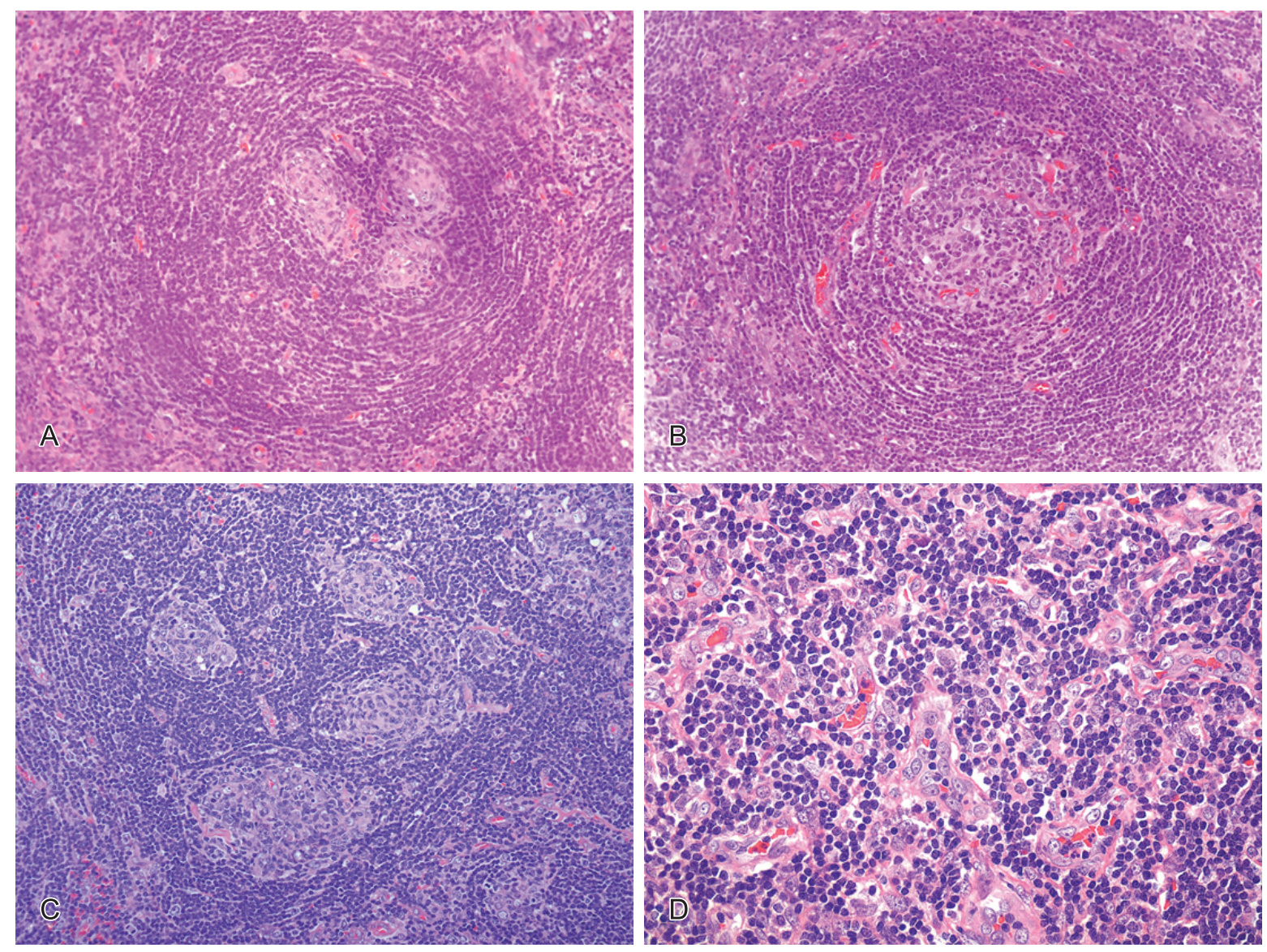

Figure 1 - Photomicrography of lymph node. A, B and C - Follicles with expanded mantle zones (onion skin) surrounding one or more atretic germinal centers with prominent vascularity; D - Vascular proliferation between the follicles, with perivascular hyalinization (HE $-400 \times)$. 

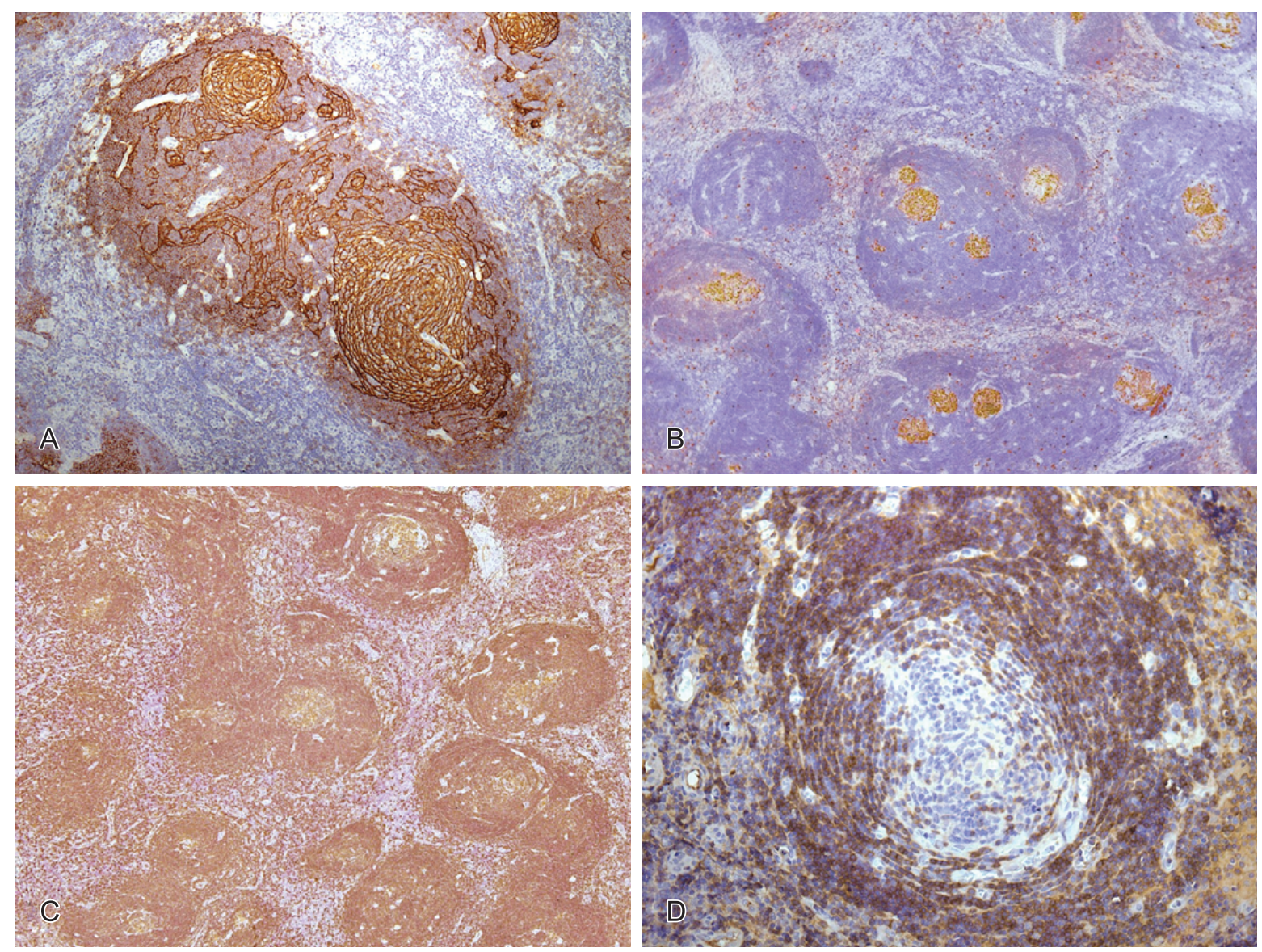

Figure 2 - Photomicrography - (immunohistochemistry, 200x). A - CD21 positive (dendritic cells); B - Ki67 positive (germinal center); $\mathbf{C}$ - CD20 positive in lymphoid follicles; $\mathbf{D}$ - IgD positive in expanded mantle zone $(200 \times)$.

distinct benign form of lymph node hyperplasia, characterized by germinal-center formation and marked capillary proliferation, which was later named as Hyaline-Vascular Castleman Disease. ${ }^{2}$ In 1969, Flendrig and Schillings described another variant of this disease known as Plasma-Cell Castleman disease. ${ }^{3}$

Castleman disease is a lymphoproliferative disorder, characterized by polyclonal B lymphocyte proliferation, ${ }^{4}$ the etiology and pathogenesis of which is not yet thoroughly understood. Although the incidence is unknown, it is increasingly relevant today due to its association with HIV and HHV-8. ${ }^{1}$

Clinically the disease is defined as unicentric or multicentric and presents three main histological variants: hyaline-vascular-, plasma cell-, and HHV8-associated Castleman disease. The first two variants are of the unicentric type, whereas the third is of the multicentric type. Plasma-cell variant may also present in the multicentric type. ${ }^{1} \mathrm{~A}$ mixed variant with features of hyaline-vascular and plasma cell variants is also recognized.
The disease is more prevalent in young adults without gender predominance, and is rare in children under the age of 18 years.

Since the first description, more than 500 cases have been reported; out of them 57 were localized on the cervical region. ${ }^{5-7}$ In adults, lesions also have been found in the thorax $(60 \%)$, abdomen $(11 \%)$, and axilla $(4 \%)^{8,9}$

In the pediatric population, until 1999, 83 cases have been reported in the literature. Most of them were localized $(86,7 \%), 27,7 \%$ in thoracic, $20 \%$ in abdominal lymph nodes, $15,6 \%$ in cervical and $6 \%$ in axillary topography. ${ }^{10,11}$ More recently, Farruggia et al (2011) reviewing pediatric cases of Castleman disease, found a number of about 100 reported cases. ${ }^{12}$ The cases of CD in childhood are mostly of unicentric hyaline-vascular type ${ }^{10}$, like in the case reported here.

The clinical features of Castleman disease are mostly related with its histological pattern. The 
hyaline-vascular type is the most common variant of Castleman disease, accounting for $70 \%$ of patients and occurring predominantly in the fourth decade of life. The lesion is usually unicentric, involving a single node or a localized group of nodes. Mediastinal involvement is most common in this variant, but may also occur in the cervical, axillary, or abdominal regions. ${ }^{1}$ Clinically it is usually asymptomatic, being incidentally identified, except when associated symptoms induced by the mass effect are present. Histologically, it is characterized by follicles with expanded mantle zones of lymphocytes arranged in concentric "onion skin" layers. The germinal centers frequently demonstrate atrophy with penetrating blood vessels. There is a prominent proliferation of germinal centers vascularity and marked interfollicular vascular proliferation with perivascular hyalinization.

The plasma cell type may be clinically of unicentric or multicentric presentation. When unicentric (10-20\% of cases), it affects an aggregate mass of lymph nodes and is accompanied by less systemic symptoms compared with the multicentric variant.

Although multicentric Castleman disease is less common $(10 \%)$, it is far more varied in clinical manifestation. Systemic symptoms are the presenting feature in most cases and may be severe and life threatening. The most common clinical findings include disseminated lymphadenopathy, constitutional symptoms, such as fever, fatigue, night sweats, malaise, hepatomegaly, splenomegaly, and skin rash. The patient may become edematous; develop ascites, pleural and pericardial effusion. ${ }^{1,13}$ In children, growth retardation may be one of the clinical symptoms. ${ }^{14}$ Laboratory findings include hypergammaglobulinaemia, chronic disease pattern anemia or hemolysis, thrombocytopenia, elevated erythrocyte sedimentation rate, hypoalbuminemia, and abnormal liver function tests. ${ }^{1}$ These clinical features seem to be related to the overproduction of IL- 6 by the affected lymph nodes. ${ }^{3,14}$ In this variant, the mean age of presentation is the sixth decade. Histologically, it is less characteristic than the hyaline vascular type. The lymph node architecture is preserved; variable germinal center hyperplasia is observed, with expanded mantle zones, and a marked paracortical plasmocytosis.

The HHV-8 associated multicentric Castleman disease is still being elucidated. It may be related to HIV coinfection, independently of the CD4 count. In this case Castleman disease is mostly of plasma cell or plasmablastic variant. HIV-associated multicentric Castleman disease generally has a rapidly progressive clinical course showing, in large series, a median survival of 14 months. The coinfection with HHV-8 may contribute to the poor outcome. ${ }^{1,15,16}$

The association of multicentric Castleman disease and non-Hodgkin lymphoma (NHL) is especially strong, but an association with Hodgkin lymphoma has also been reported. Besides the coexistence of Castleman disease and lymphoma, the progression of multicentric Castleman disease into lymphoma has also been reported. ${ }^{1}$ In a prospective study involving 60 patients with multicentric Castleman disease and HIV, who were followed for 20 months, $23 \%$ developed NHL, at least half of which was aggressive plasmablastic lymphoma. ${ }^{1,15,17}$ A recent report shows an association with Epstein-Barr virus infection and Castleman disease, by extraction of DNA from 18 cases of unicentric Castleman disease and 1 case of multicentric Castleman disease. This hypothesis has still to be validated since other reports failed to show this relationship. ${ }^{18,19}$

Castleman disease occurs frequently in association with autoimmune disease, and they likely share many features of pathophysiology. Among these autoimmune disorders are, systemic lupus erythematous, rheumatoid arthritis, scleroderma, polymyositis, mixed connective tissue disease, myasthenia gravis, paraneoplastic pemphigus, Evan's syndrome, glomerulopathy, and POEMS (polyneuropathy, organomegaly [particularly hepatosplenomegaly], endocrinopathy, monoclonal gammopathy, and skin changes). ${ }^{4}$

Castleman disease is usually not the first suspicion for neck masses. The differential diagnosis includes infectious and inflammatory lesions such as nonspecific lymphadenitis, tuberculosis, sarcoidosis, toxoplasmosis, cytomegalovirus, as neurofibroma, cervical lipoma, thymoma, Hodgkin disease, $\mathrm{NHL}$, and lymph node metastasis must be included ${ }^{3}$ in the differential diagnosis workup as well.

The diagnosis of Castleman disease is histopathological since most imaging diagnostic exams, such as computed tomography (CT) or magnetic resonance imaging (MRI) may help, but there is a lack of specific findings. Positron emission tomography-CT (PET-CT) scanning is effective in the diagnostic workup of unicentric or multicentric 
Castleman disease as well as in the follow-up examinations. ${ }^{13}$ PET-CT is able to detect abnormal high uptake in non-enlarged nodes as well, thus helping in more accurate staging and monitoring of the disease. ${ }^{20}$

The treatment of choice for the unicentric hyaline-vascular variant is surgical excision, which is accompanied by good prognosis. In this case, surgical excision promoted the diagnosis as well as the therapeutics, providing a complete recovery. ${ }^{21,22}$ On the other hand, due to its disseminated nature, complete resection is rarely possible for the multicentric type, therefore demanding systemic therapy. In this setting, high doses of steroids, chemotherapy alone, combined therapy and antiIL-6 monoclonal antibodies ${ }^{7}$ are used, despite the poor prognosis characteristic of this variant.

\section{CONCLUSION}

Due to the low incidence of Castleman disease and the physician's unfamiliarity, misdiagnosis or delayed diagnosis is frequent. This observation becomes more relevant in pediatrics. Therefore the disease has to be included in the differential diagnosis of lymph node enlargement, anemia and B-symptoms. In the localized diseases, total tumoral exeresis should be performed for both therapeutic and diagnostic purposes.

\section{REFERENCES}

1. Dham A, Peterson B. Castleman disease. Curr Opin Hematol. 2007;14:354-9. http://dx.doi.org/10.1097/ $\mathrm{MOH} .0 \mathrm{~b} 013 \mathrm{e} 328186 \mathrm{ffab}$

2. Castleman B, Iverson L, Menendez VB. Localized mediastinal lymph node hyperplasia resembling thymoma. Cancer. 1956;9:822-30. http://dx.doi. org/10.1002/1097-0142(195607/08)9:4\%3C822::AIDCNCR2820090430\%3E3.0.CO;2-4

3. Cronin DM, Warnke RA. Castleman disease. An update on classification and the spectrum of associated lesions. Adv Anat Pathol. 2009;16:236-46. http://dx.doi.org/10.1097/ PAP.0b013e3181a9d4d3

4. Muskardin TW, Peterson BA, Molitor JA. Castleman disease and associated autoimmune disease. Curr Opin Rheumatol. 2012;24:76-83. http://dx.doi.org/10.1097/ BOR.0b013e32834db525
5. Lin CY, Huang TC. Cervical posterior triangle castleman's disease in a child - case report \& literature review. Chang Gung Med J. 2011;34:435-9.

6. Minerva T, Franza R. Castleman's disease with diffuse cervical localization: case report. Acta Otorhinolaryngol Belg. 2004;24:234-8.

7. Rao HG, Srteet I, Capper R. Unusual location for Castleman's disease. J Laryngol Otol. 2009;123:e3. http://dx.doi. org/10.1017/S0022215108004180

8. Anagnostou D, Harrison CV. Angiofollicular lymph node hyperplasia (Castleman). J ClinPathol. 1972;25:306-11. http://dx.doi.org/10.1136/jcp.25.4.306

9. Zhong LP, Chen GF, Zhao SF. Cervical Castleman disease in children. Br J Oral Maxillofac Surg. 2004;42:69-7. http:// dx.doi.org/10.1016/S0266-4356(03)00204-3

10. Souza KC, Silva SJ, Salomão E, et al. Cervical Castleman's disease in childhood. J Oral Maxillofac Surg. 2008;66:106772. http://dx.doi.org/10.1016/j.joms.2007.06.678

11. Parez N, Bader-Meunier B, Roy CC, et al. Paediatric Castleman disease: report of seven cases and review of literature. Eur J Pediatr. 1999;158:631-7. http://dx.doi. org/10.1007/s004310051166

12. Farruggia $P$, Trizzino A, Scibetta N. Castleman's disease in childhood: report of three cases and review of the literature. Ital J Pediatr. 2011;37:50. http://dx.doi.org/10.1186/18247288-37-50

13. Yin L, Lu XY, Xu F,Li AJ, Wu MC. Unicentric Castleman's disease presenting with growth retardation and iron deficiency anemia. Am J Med Sci. 2012;343:426-8. http://dx.doi. org/10.1097/MAJ.0b013e318242a212

14. Galeotti C, Boucheron A, Guillaume S, Koné-paut I. Sustained remission of multicentric Castleman disease in children treated with tocilizumab, an Anti-interleukin-6 receptor antibody. Mol Cancer Ther. 2012;1-4. http://dx.doi.org/10.1158/1535-7163. MCT-11-0972

15. Casper $\mathrm{C}$. The aetiology and management of Castleman disease at 50 years: translating pathophysiology to patient care. Br J Haematol. 2005;129:3-17. http://dx.doi.org/10.1111/ j.1365-2141.2004.05311.x

16. Oksenhendler E, Duarte M, Soulier J, et al. Multicentric Castleman's disease in HIV infection: a clinical and pathological study of 20 patients. AIDS. 1996;10:61-7. http:// dx.doi.org/10.1097/00002030-199601000-00009

17. Oksenhendler E, Boulanger E, Galicier L,et al. High incidence of Kaposi sarcoma-associated herpesvirus-related nonHodgkin lymphoma in patients with HIV infection and multicentric Castleman disease. Blood. 2002;99:2331-6. http://dx.doi.org/10.1182/blood.V99.7.2331

18. Chen YF, Zhang WD, Sun CZ, et al. Clinical features and outcomes of head and neck Castleman disease. J Oral 
Maxillofac Surg. 2012 Jan; [Epub ahead of print; cited 2012 Jul 20]. Available from: http://www.sciencedirect.com/science/ article/pii/S0278239111017757\#. http://dx.doi.org/10.1016/j. joms.2011.12.002

19. Chen $\mathrm{CH}$, Liu HC, Hung TT, et al: Possible roles of EpsteinBarr virus in Castleman disease. J Cardiothorac Surg. 2009;4:31. http://dx.doi.org/10.1186/1749-8090-4-31

20. Madan R, Chen JH, Trotman-Dickenson B, Jacobson F, Hunsaker A. The spectrum of Castleman's disease: Mimics, radiologic pathologic correlation and role of imaging in patient management. Eur J Radiol. 2012;81:123-31. http://dx.doi. org/10.1016/j.ejrad.2010.06.018

21. El Massaoudi A, El Edghiri $H$, Lazrak A, et al. Castleman disease. Apropos of 2 cervical localizations. Rev Laryngol Otol Rhinol (Bord). 1993;114:189-91.

22. Majercakova D. Castlemans disease. Vnitr Lek. 2012;58:216-20.

\section{Conflict of interest: None}

Submitted on: $13^{\text {th }}$ july 2012

Accepted on: $28^{\text {th }}$ august 2012

Correspondence: Departamento de Patologia

Faculdade de Medicina da Universidade de São Paulo

Av. Dr. Eneas Carvalho de Aguiar, 155, $10^{\circ}$ andar - Cerqueira Cesar - São Paulo/SP - Brasil

CEP: $055403-000$ - Phone: +55 (11) 2261.7996

E-mail: viannapaula@hotmail.com 